Swarthmore College

Works

6-1-2016

\title{
Knowledge Across Contexts. A Problem For Subject-Sensitive Invariantism
}

Peter Baumann

Swarthmore College, pbauman1@swarthmore.edu

Follow this and additional works at: https://works.swarthmore.edu/fac-philosophy

Part of the Philosophy Commons

Let us know how access to these works benefits you

\section{Recommended Citation}

Peter Baumann. (2016). "Knowledge Across Contexts. A Problem For Subject-Sensitive Invariantism". Dialogue: Canadian Philosophy Review. Volume 55, Issue 2. 363-380. DOI: 10.1017/S0012217316000317 https://works.swarthmore.edu/fac-philosophy/453

This work is brought to you for free by Swarthmore College Libraries' Works. It has been accepted for inclusion in Philosophy Faculty Works by an authorized administrator of Works. For more information, please contact myworks@swarthmore.edu. 


\section{Knowledge across Contexts. A Problem for Subject-Sensitive Invariantism}

Penultimate Version. Forthcoming in: Dialogue: Canadian Philosophical Review. See also: Cambridge Journals Online. Copyrights: Canadian Philosophical Association.

PETER BAUMANN Swarthmore College

\section{ABSTRACT}

The possibility of knowledge attributions across contexts (where attributor and subject find themselves in different epistemic contexts) can create serious problems for certain views of knowledge. Amongst such views is subject-sensitive invariantism-the view that knowledge is determined not only by epistemic factors (belief, truth, evidence, etc.) but also by non-epistemic factors (practical interests, etc.). I argue that subjectsensitive invariantism either runs into a contradiction or has to make very implausible assumptions. The problem has been very much neglected but is so serious that one should look for alternative accounts of knowledge.

\section{The Problem: A Contradiction for SSI}

Hawthorne and Stanley are on a train, in different coaches. They both independently wonder whether the train will stop at T-town. A lot depends on it for Stanley but nothing for Hawthorne. They look up the reliable schedule which says, correctly, that the train does stop at T-town. Can they thus come to know that the train will stop at $\mathrm{T}$ town $?^{1}$

According to subject-sensitive invariantism (SSI), knowledge does not only depend on the epistemic situation of the subject (true belief, warrant) but also on their 
non-epistemic situation, especially their practical interests. ${ }^{2}$ If the practical stakes (for a person at a time) go up or down, they drive the standards for knowledge up or down. In high—stakes situations it is harder to know a given proposition than in low-stakes situations. It can happen that one and the same proposition is known by a subject in a low—stakes situation and not known by a subject in a high—stakes situation, even if the two subjects do not differ with respect to the relevant epistemic factors (evidence, etc.). ${ }^{3}$

According to SSI, Hawthorne might well come to know (by trusting the schedule) that the train will stop at T-town whereas Stanley would probably not come to know that (until he checks further sources, asks the conductor, etc.; let us assume for the sake of the example that only very special, direct perceptual evidence would constitute warrant sufficient for knowledge). Suppose Hawthorne knows that the train will stop at T-town whereas Stanley doesn't. Also suppose that Stanley hears from another passenger passing through his coach that reliable Hawthorne carefully examined the schedule and came to the conclusion that the train will stop at T-town; "Hawthorne knows that the train will stop at T-town," the passenger tells Stanley. Let us add further that Stanley also adheres to SSI. Can he, after correctly evaluating their situation,

2 See Hawthorne 2004; Stanley 2005; Fantl and McGrath 2009

3 Strictly speaking, this is only one though a widely accepted version of SSI. The non-epistemic parameter need not be restricted to practical interests and the latter do not even have to be amongst the relevant non-epistemic factors. For the sake of simplicity, I will only consider the interest-relative version of SSI (also because it is the most widely discussed one). The arguments here also apply to other (e.g., salience-based; see Hawthorne 2004, ch.4) versions of SSI. I will also leave aside the non-trivial question as to what distinguishes epistemic from non-epistemic factors. 
concede that whereas he himself doesn't know that the train will stop at T-town, Hawthorne does?

If yes, then SSI is in trouble. ${ }^{4}$ This problem has been neglected so far. ${ }^{5}$ Here is the problem. According to SSI, the following two things are true (given our little story):

(1) Hawthorne knows that the train will stop at T-town;

(2) Stanley doesn't know that (whether) the train will stop at T-town.

Now, let us assume that Stanley, the adherent of SSI, does concede and even know (1). Can't one person very often or normally know that another person knows a given proposition? This possibility seems so basic for our ordinary concept of knowledge that its denial would have to be supported by strong theoretical reasons against it (see much more on this below). Lacking such overriding reasons, we can allow for the possibility that and assume that

4 Similar problems arise, more indirectly, for arguments supporting SSI, like, e.g., arguments from a close connection between knowledge and practical reasoning or action (see, e.g., Williamson 2005, 231, and 2000, 47; Stanley 2005, 9-10; Hawthorne 2004, 29-30, 85, 174-175; Hawthorne and Stanley 2008; Fantl and McGrath 2009). I won't go into this (but see Baumann 2012) or other arguments for SSI here because they're not relevant to my main point.

5 But cf. the short passages in Wright 2005, 243-244; Brueckner 2005, 317; Hawthorne 2004, 159-160; one of the very few papers on the topic is Brueckner and Buford 2009; see also Williamson 2005, sec.2 as well as Macfarlane 2005, Blaauw 2008, Brown 2014, 192-196, and Moeller 2015 on related problems concerning testimony and memory. On the analogous problem for contextualism see also Baumann 2008. 
(3) Stanley knows that Hawthorne knows that the train will stop at T-town.

Stanley further knows that

(Factivity) For all subjects $\mathrm{S}$ and all propositions $p$ : If $\mathrm{S}$ knows that $p$, then $p .^{6}$

Hence it is also true that (given that Stanley can apply (Factivity) to cases)

(4) Stanley knows that if Hawthorne knows that the train will stop at T-town, then it will stop at T-town.

Given closure (or a basic form thereof)_-

(Closure-Basic) For all subjects $S$ and all propositions $p$ and $q$ : If $S$ knows that $p$ and also knows that $(p \rightarrow q)$, then $S$ knows that $q^{7}$

-we can infer from (3) and (4) that

6 This holds with necessity. For the sake of simplicity, I will skip the necessity operator here and below in the case of this and other necessary principles.

7 This is a simplified version of an acceptable principle of closure. One would have to add further whistles and bells, like the condition that the person competently deduces $q$ from $p$ and $p \rightarrow q$. We can skip this and other such details here because they don't matter for the main point here. 
(5) Stanley knows that the train will stop at T-town.

This, however, contradicts (2). Which assumption has to go ${ }^{8}$ In the following I will lay out several possible strategies for the adherent of SSI to solve this problem (section 2). The following sections (3-5) argue against the one, initially promising strategy. I will also point out unwelcome implications of this defence of SSI (sections 6-7) and end by discussing a lost proposal to solve the problem for SSI (section 8).

\section{Denying Knowledge of Knowledge}

It seems very desperate to deny factivity. If anything does not satisfy the factivity condition, then it is not knowledge; factivity seems essential to and at least partly constitutive of knowledge. Apart from this, even if one were to give deniers of factivity some credibility, that denial wouldn't help the defender of SSI much at all: They need an independent motivation for it which goes beyond the ad hoc reason that the denial of factivity would solve a problem for the theory. Rescuing an interesting epistemological

8 All I am arguing for here is that SSI leads to contradictions not in all but only in some though important cases: when the stakes of the person who makes the relevant cross-context judgments are significantly higher than the stakes of the other subject. This is sufficient to get SSI into serious trouble. The problem presented here arises in a pure third-person form. There is no element of some irreducible first-person perspective that is doing any work in the exposition of the problem (no matter whether Stanley believes or knows that he is indeed Stanley). There is thus also no shift (legitimate or illicit) between first- and third-person perspectives involved here. Thanks to a referee for pressing me on this. 
view by giving up on one of the least controversial basic assumptions about knowledge constitutes a very desperate move.

But what about denying closure or at least a principle like (Closure-Basic) above? Such principles are, though accepted quite broadly, much less uncontroversial than the factivity assumption, and there have been prominent and very well—argued deniers of such principles. ${ }^{9}$ What reason then could one have to deny something like (Closure-Basic)? And what reasons of that kind would be relevant here? Dretske, for instance, argues that closure fails in cases where the conclusion of the relevant deduction ('q') constitutes a 'heavyweight proposition'. ${ }^{10}$ Dretske is thinking of denials of sceptical scenarios (like, e.g., I am not currently being deceived by a Cartesian demon) when referring to heavyweight propositions. It seems obvious that a proposition like the one in (5) (that the train will stop at T-town) does not qualify as such a heavyweight proposition. There certainly are lightweight propositions in Dretske's sense and the latter one belongs into this class. Hence, Dretske's analysis doesn't help us with our problem.

Nozick also does not help us much in our search for independent non—ad-hoc reasons to give up the likes of (Closure-Basic). He states that such a principle is incompatible with his own account of knowledge ${ }^{11}$ but also adds an (astonishingly rarely discussed) diagnosis of closure failure. According to him, closure fails in cases where if the conclusion ('q') were false, the subject would still believe the premise ('p') and

9 See Dretske 1970 and Nozick 1981, ch.3.

10 See Dretske 2005, 16-17.

11 See Nozick 1981, ch.3.I-II. 
deduce the conclusion from it. ${ }^{12}$ If the train were not to stop at T-town (see (5)), Stanley might still believe that Hawthorne knows that the train will stop at T-town (see (3)) and infer that the train will stop at T-town. However, even if our case can be diagnosed by Nozick, his diagnosis still doesn't offer us an independent reason (which would not be ad hoc) to deny (Closure-Basic) or anything like it. How could it?

Does closure perhaps fail in cases where there is some kind of "transmission failure" $?^{13}$ Here is what one could have in mind: Closure fails in cases where the conclusion ('q') is antecedently (to the inference) unknown by the subject but the subject's knowledge that $p$ requires that she presupposes and takes for granted that $q$. Whatever the details of such an idea, it is very hard to see in our case how Stanley's knowledge of the premise (that Hawthorne knows that the train will stop at T-town) requires the presupposition of the antecedently unknown conclusion (that the train will stop at T-town) (see also section 5 below). Finally, one might propose that closure fails in cases where the premises are of low stakes (e.g., that Hawthorne knows that the train will stop at T-town) but the conclusion is of high stakes (e.g., that the train will stop at T-town). Such a move also seems poorly motivated and ad hoc (see also section 4 below).

Let us then put both the denial of closure and the denial of factivity aside as potential strategies to solve our problem, without going further into these complex topics (I can, by the way, think of no defender of SSI who would be ready deny either of the

12 See Nozick 1981, 231.

13 See for this idea Wright 1985, 432-438, and Davies 1998, 351-355; however, both distinguish in principle between transmission failure and closure failure. 
two). It would also be ad hoc to deny that Stanley can know some instance of the Factivity principle like the one in (4). Hence, we are left with (1), (2) and (3): that Hawthorne knows but Stanley doesn't know that the train will stop at T—-town, and that Stanley knows that Hawthorne knows it. (1) and (2) follow from SSI (given our case). What then about (3) (Stanley knows that Hawthorne knows that the train will stop at Ttown) ? Couldn't or shouldn't Stanley or the adherent of SSI in a high—stakes situation deny that they know (1) $?^{14}$ Stanley cannot know (1), so the argument goes, not because he doubts that Hawthorne has a warrant—based belief that the train will stop at Ttown. Rather, given the high stakes, he cannot commit himself to or accept $p$. He does not know $p$ and does not take himself to know $p$. But given factivity and closure (see section 1 above) he would need to know $p$ in order to know that Hawthorne knows it. To be sure, Stanley can accept the conditional If the train will stop at T-town, then Hawthorne knows that but this is neither here nor there because it doesn't amount to the unconditional claim needed here: that Hawthorne knows that the train will stop at T-town.

Let us take a closer look at this point: How exactly would the argument against (3) (Stanley knows that Hawthorne knows that the train will stop at T-town) work? It certainly cannot be the following one: (5) (Stanley knows that the train will stop at $T$ town) is false; (5) follows from (3), (4) (Stanley knows that if Hawthorne knows that the train will stop at T-town, then it will stop at T-town) and closure: hence the conjunction of (3), (4) and closure is false; since closure and (4) are beyond doubt here, (3) is false. In short: since Stanley does not know that $p$ he cannot know that Hawthorne 
knows that $p$ (which together with plausible principles implies the former). This argument, however, would, as it stands, simply be question—begging and a case of ignoring the problem of inconsistency from the start; to resolve a contradiction like the one above ( $p$ and not- $-p$ ), one certainly cannot reject $p$ on the basis of not-p. And isn't (3) independently plausible? I only mention this kind of weak argument because some people bring it up in discussion; therefore it is worth mentioning it, if only to get it out of the way. ${ }^{15}$

What other ways of arguing against (3) are there? Unfortunately for SSI, there is (as we will see) no room for the denial of (3) or for the affirmation of

(6) Stanley does not know that / whether Hawthorne knows that the train will stop at Ttown.

How could (6) be true?

Why shouldn't Stanley be able to come to acquire knowledge about Hawthorne's epistemic state (e.g., via testimony), especially if he happens not to care much about Hawthorne and his epistemic states? Doesn't a theory which denies this basic possibility have to come up with strong reasons against it? Isn't the burden of proof on the side of SSI here? SSlists will and should argue that Stanley is in a high-stakes situation with respect to Hawthorne's epistemic situation concerning $p$ because Stanley is in a high—stakes situation with respect to $p$; therefore Stanley cannot come to know that $p(1)$. But couldn't Stanley be in a low-stakes situation with respect to Hawthorne's 
epistemic situation concerning $p$ even if $p$ is a high—stakes proposition for Stanley? I will argue step by step for a positive answer to this question. In section 3 I will start to raise doubts about the idea of a close connection between the stakes for $p$ and the stakes for $K p$; this section is of a preparatory nature. In sections 4 and 5 I will continue and discuss what are probably SSI's defenders' main arguments here. In sections 6 and 7 I will discuss bad implications of all these defences of SSI while I briefly discuss a last proposal of a way out of the problem for SSI in section 8 .

\section{First Failed Argument: P-Stakes and Kp-Stakes}

Certainly, the stakes regarding a given proposition can be different from the stakes regarding somebody else's knowledge of that proposition. The following principle is false:

(Hand-in-Hand) For all subjects $\mathrm{A}$ and $\mathrm{S}$ and all propositions $p$ : A's stakes regarding $p$ are not significantly higher and not significantly lower than A's stakes regarding $S$ knows that $\mathrm{p}$.

A might not care at all whether Cairo is the capital of Egypt but care a lot whether $S$ knows whether Cairo is the capital of Egypt, given that $S$ is on a game show, would win a lot money with a correct answer to a question about Egypt's capital and has promised to split all gains with A. So, someone's stakes can be low regarding a given proposition but high when it comes to whether someone else knows that proposition. 
One could object that in this case part of A's concern whether $S$ knows that $p$ is the concern whether $p$ (at least sometimes a concern for $\mathrm{X}$ involves a concern for some necessary condition $Y$ of $X)$. However, the focus of A's concern in the case above is clearly on S's epistemic situation with respect to the relevant fact; there is thus much less of a focus on the fact itself. A's stakes are higher with respect to the former than with respect to the latter aspect of the situation (even if both are connected). Apart from that, it is not true for all necessary conditions $Y$ of some given $X$ that high stakes for $X$ come with high stakes for $\mathrm{Y}$ : Even if Jack is coming to town is high stakes for Jill at $\mathrm{t}$, it need not be high stakes at all for Jill whether someone is coming to town.

The reverse case is much more interesting, controversial and relevant here: Can someone's stakes be high regarding a given proposition but low when it comes to whether someone else knows that proposition? Can Stanley have high stakes regarding the train stops but low stakes regarding Hawthorne's knowledge of it? The defender of SSI might reply that

(Hand-in-Hand ${ }^{*}$ ) For all subjects $A$ and $S$ and all propositions $p$ : A's stakes regarding $p$ are not significantly higher than A's stakes regarding $S$ knows that $p$.

Suppose I care a lot whether my grandparent G died without pain. There is nothing I can do about it but my stakes are still high here: A death in pain would depress me quite a bit while a painless death would relieve me considerably. Are my stakes then for, say, G's neighbour knew that $G$ died with/ without pain as high (more or less)? I don't think so. My concern is with the fact and not so much with my neighbour's epistemic situation. 
It might be harder to argue against (Hand-in-Hand*) when the subject is about to act on the relevant proposition. Here is an example including such a direct connection with action. I care a lot whether the mushrooms I am going to cook are of a certain (poisonous) kind. Are my stakes regarding Cambridge's mushroom expert Dr. F knows that these mushrooms are / aren't of a certain (poisonous) kind as high (more or less) as my stakes concerning These mushrooms are / aren't of a certain (poisonous) kind? Assume in addition that Cambridge has 4 famous mushroom experts. Are the stakes regarding each of the following group then as high as regarding the original proposition:

Dr. A knows that the mushrooms are / aren't poisonous, Dr. C knows that the mushrooms are / aren't poisonous, Dr. E knows that the mushrooms are / aren't poisonous, Dr. F knows that the mushrooms are / aren't poisonous,

I doubt it. My concern is not with the question whether this or that expert knows that $p$; I am more concerned with the question whether someone knows that $p$ and even more (much more) concerned with the question whether $p .{ }^{16}$

16 One could propose to replace (Hand-in-Hand*) by (Hand-in-Hand $\left.{ }^{* *}\right)$ : For all subjects $\mathrm{A}$ and $S$ and all propositions $p$ : A's stakes regarding $p$ are not significantly higher than A's stakes regarding Somebody knows that p. Perhaps the latter is more plausible than the former. However, I doubt that it is plausible enough here. I won't go into this any further because this section is only supposed to raise some doubts about claims that stakes are connected a certain way. 
If I am right and if (Hand-in-Hand*) is false, then it seems quite plausible to say that Stanley can come to know that Hawthorne knows that the train stops at $\mathrm{T}$ town even if Stanley does not know that the train will stop at T-town. According to SSI's own principles, we would then have to say that Stanley knows that Hawthorne knows - and accept the contradiction. However, as I said above, I don't take this section to be anything but preparatory for what follows now.

\section{Second Failed Argument: Transmission of Stakes}

There is an argument against (3) (Stanley knows that Hawthorne knows that the train will stop at T-town) and the inconsistency claim which I have encountered quite often in discussion and which seems to capture the main point of resistance against the conclusion I am arguing for. Here it is, as applied to our original example. Stanley's stakes are high with respect to (1) (Hawthorne knows that the train will stop at $T$-town) because he can deduce from (1) together with some other premise (Factivity) a proposition which is high—stakes for him, namely that the train will stop at T-town. ${ }^{17}$ This thought suggests something like the following general principle as its basis (we can ignore details and possible variations here):

17 See Stanley 2005, 93-94 for a hint in this direction; see also the related discussion of Neta 2007 in Fantl and McGrath 2009, 201-207 and another round in Neta 2012, 459-460 and Fantl and McGrath 2012, 482-484; see also Montminy and Skolits 2014, 324 and in particular Howell 2005. 
(Inferential Stakes) For all subjects $\mathrm{S}$ and all propositions $p, q$ and $r$ : If $p$ is a highstakes proposition for $S$ and if $S$ can deduce $p$ from $q$ (together with some $r$ ), then $q$ is itself a high—stakes proposition for S.

The defender of SSI will have to accept something along these lines. Just to mention another variation-a principle in terms of entailment rather than deducibility by S:

(Entailed Stakes) For all subjects $\mathrm{S}$ and all propositions $p, q$ and $r$ : If $p$ is a high—stakes proposition for $\mathrm{S}$ and if $q$ (together with some $r$ ) entails $p$, then $q$ is itself a high-stakes proposition for S.

The problem is that such principles are incorrect. First of all - as already pointed out above-, stakes don't transfer to necessary conditions automatically or in every case: so, low stakes for $K p$ don't entail low stakes for $p$ and not so low stakes for $p$ don't entail not so low stakes for $K p$. Let us look more closely at the following three problems.

Obviously (i), every proposition $q$ entails some high-stakes proposition $p$ if combined with certain other appropriate premises (whether of the form 'If $q$ then $p$ ' or not). Hence, according to (Entailed Stakes) every proposition is a high-stakes proposition if some are. Since some are, every proposition is a high-stakes proposition. This, however, seems clearly false: Clearly, stakes differ from proposition to proposition (for a subject at a time). Defenders of SSI should try not to get into a situation where they have to deny this. A similar argument can (with slight modifications) be made against (Inferential Stakes)—but I won't go into this here to avoid repetitions. 
Consider also (ii) an example involving a great number of premises from which a high—stakes conclusion can be inferred. Suppose a detective is working on some case. There are 1000 different propositions describing different pieces of evidence. Only taken together they do imply a proposition which is of high stakes for the detective (namely that the chauffeur did it). It is very implausible that a particular single, isolated piece of evidence as such (e.g., that the profile of the tires of the chauffeur's private car is medium) should count as being of high stakes for the detective. Again, similar things hold (mutatis mutandis) for (Entailed Stakes).

Finally (iii), Stanley uses both (1) (Hawthorne knows that the train will stop at $T$ town) and (Factivity) to infer the high—stakes (for him) proposition that the train will stop at T-town. If this makes (1) high—stakes, then presumably it also makes (Factivity) high—stakes. The latter, however, is very implausible. But then it seems arbitrary to say that (1) is high—stakes for Stanley-given that (Factivity) is not. Why should one premise be high—stakes and the other not? Even if one were to restrict (Inferential Stakes) and (Entailed Stakes) to a small number of (types of) premises, one would still have to explain which propositions would be high—stakes given that they help infer or entail a high—stakes proposition and which propositions wouldn't be high—stakes for that reason. There are serious doubts that this can be done in any non-arbitrary way. SSlists have, as far as I can see, not even begun to try to do this. As long as this is the case, we should reject the likes of (Inferential Stakes) and (Entailed Stakes) and not bet 
much on them. They don't give any plausible support to (6) and won't help against the inconsistency claim. $^{18}$

\section{Third Failed Argument: Independent and Prior Knowledge}

There is another move the defender of SSI could make when arguing for (6) (Stanley does not know that / whether Hawthorne knows that the train will stop at T-town): adding further necessary conditions for knowing that someone else knows that $p$. What Stanley apparently needs for knowledge that $S$ knows that $p$ is prior, independent knowledge that $p$, that is, knowledge that $p$ which is not based on the knowledge that $S$ knows that $\mathrm{p}$; Stanley needs to base his knowledge of (1) (Hawthorne knows that the train will stop at T-town) on his knowledge of The train will stop at T-town. However, this kind of independent, prior knowledge of The train will stop at T-town Stanley does not have in his high—stakes situation. This is why Stanley does not have knowledge of (1).

However, there is a serious problem with this move: It presupposes a principle like the following one:

18 If principles like (Inferential Stakes) or (Entailed Stakes) are false, and if in general degrees of stakes are not closed under known entailment, then one might wonder how the defender of SSI can hold on to a principle of closure for knowledge (which would be particularly interesting given the problems with giving up closure mentioned above, at the beginning of section 2). See Stanley 2005, 93-94 here but also Fantl 2015, 41-42. This is not our concern here. 
(Independent Knowledge) For all subjects $\mathrm{A}$ and $\mathrm{B}$ and all propositions $p$ : If $\mathrm{A}$ knows that $\mathrm{B}$ knows that $p$, then $\mathrm{A}$ knows that $p$ where the latter knowledge is prior to and independent from (not based on) the knowledge that B knows that $p$.

However, (Independent Knowledge) is not plausible. ${ }^{19}$ Consider a case of testimony. A reliable and trustworthy informant tells the mathematical lay person Jack that Wiles knows that Fermat was right. It seems that Jack thus acquires knowledge that Wiles knows that Fermat was right even if Jack has no independent and prior knowledge that Fermat was right. Why then should Stanley not also acquire testimonial knowledge that Hawthorne knows that $p$ (e.g., from an omniscient God who also believes in SSI or from some fellow SSlist how has much better evidence available both about the train schedule and Hawthorne's epistemic situation) without having any independent knowledge of $p$ himself? It would be a bad idea to reply dogmatically here that (Independent Knowledge) is true or to refer back to principles like (Inferential Stakes) or (Entailed Stakes). Hence, we get right back into the initial contradiction. ${ }^{20}$

19 It is only plausible in special cases of first-person attributions; see Montminy and Skolits 2014, 325.

20 Reductionists about testimony (see, amongst many, Fricker 1987) might protest here. According to them, one can only acquire knowledge of $p$ through testimony if one has independent knowledge of the trustworthiness of the testifier or the reliability of the testimony (antireductionists about testimony deny all this). According to this idea, Stanley would need prior and independent knowledge of the trustworthiness of the testifier or the reliability of the testimony. And this latter knowledge he might lack in his high—stakes situation. This counter-reply faces three problems. First, even if reductionism is true and the subject needs independent knowledge of the trustworthiness of the testifier or the reliability of the testimony, this still does not establish 
Could a principle weaker than (Independent Knowledge) help the defender of SSI at this point? Consider

(Counter-KK) For all subjects $A$ and $B$ and all propositions $p$ : If $A$ knows that $B$ knows that $p$, then A knows that $p$.

(Counter-KK) follows from and does not entail (Independent Knowledge) which is a special case of (Counter-KK).

If (Counter-KK) is true, then it seems that the defender of SSI can use it in order to reject (3) (Stanley knows that Hawthorne knows that the train will stop at T-town). Using modus tollens, they can argue that since Stanley does not know that the train will stop at T-town, he also does not know that Hawthorne knows that the train will stop at T-town.

But is (Counter-KK) true? A's knowledge that $p$ is either

(i) prior to and independent from (not based on) the knowledge that $\mathrm{B}$ knows that $p$,

or

that the subject also needs independent knowledge of the testified content. Second and apart from that, this counter-reply would help to defend a general account of knowledge by using a very specific view about a particular source of knowledge; this, however, seems to get the cart before the horse. Third and related to the last point, anti-reductionism is a controversial view about testimony and it does not seem wise to add such burdens of proof to one's case for SSI. 
(ii) not prior to or independent from (not based on) the knowledge that B knows that $p$.

Given the argument against (Independent Knowledge above), we can leave (i) aside here. This leaves us with (ii). If the defender does not want to present the questionbegging argument discussed above (section 2), then they could only have in mind the case where A's knowledge that $p$ is based (typically: inferentially) on A's knowledge that B knows that $p$. Section 8 below will reject this option, and I refer the reader to that later section. So, both (Independent Knowledge) and (Counter-KK) are false. Our problem for SSI remains on the table.

\section{Troubling Implications: Blindspots}

No matter whether one goes with the first, second or third strategy of defending SSI (sections 3-5), there are further problems with the idea that Stanley does not know (1) (Hawthorne knows that the train will stop at T-town) because he lacks knowledge of The train will stop at T-town. These problems have to do with the implications the acceptance of (6) (Stanley does not know that / whether Hawthorne knows that the train will stop at T-town) would have for SSI. Here is a first one:

(Blindspot) For all subjects $A$ and $B$ and all propositions $p$ : If $A$ is in a high-stakes situation such that $\mathrm{A}$ does not know that $p$, and $\mathrm{B}$ is in a low-stakes situation such that B knows that $p$, then $A$ does not know that $B$ knows that $\mathrm{p}$. 
We can assume that the antecedent of (Blindspot) is quite often true. According to SSI, there would then be lots of quite simple truths about the knowledge of other people of which we would quite often have no knowledge. This is a serious limitation. Furthermore, people usually hold that they don't suffer from this kind of epistemic limits ("Perhaps the threat of a Cartesian demon is a problem but not this!"). If that is so, the adherent of SSI would also have to add some plausible error theory which explains why subjects can get things so wrong so often. This is not an attractive situation for theorists (like the typical SSlists) who like to avoid attributing systematic error to subjects.

One could object that the antecedent (Blindspot) is not that often true: only when A finds themselves in extraordinary situations of considerably high stakes. But this, the objection would continue, does not happen that often. In response one should stress that high—stakes situations do not have to be situations of extraordinarily high stakes. All that is needed for (Blindspot) to be true is that A's stakes are higher than B's such that $\mathrm{B}$ knows that $p$ whereas $\mathrm{A}$ does not know that $p$. Lacking an argument for the implausible assumption that rarely the stakes differ significantly for different subjects in a given situation, the remarks just made are support for the claim that (Blindspot) will be true quite often, given SSI.

Unsurprisingly, the situation is additionally embarrassing for the adherent of SSI. Stanley can reflect on all the above. If he does, he will have to admit that

(7) I don't know whether Hawthorne knows that the train will stop at T-town but if I simply switch to a low-stakes situation I might well know that. 
This is a well-known problem for SSI and looks like an abominable conjunction ${ }^{21}$ and perhaps even paradoxical. ${ }^{22}$

\section{More Troubling Implications: What to Think about Hawthorne?}

There is another worrisome implication of the above defences of (6) (Stanley does not know that / whether Hawthorne knows that the train will stop at T-town) and SSI worth mentioning here. What should Stanley believe about Hawthorne's epistemic state, according to SSI? Should he believe (1) or its negation or, perhaps suspend belief? If Stanley believes that

(1) Hawthorne knows that the train will stop at T-town,

then he should also, given normal inferential abilities and knowledge of (Factivity), believe that

(8) The train will stop at T-town.

But how can Stanley believe this if at the same time he, given his high stakes, cannot commit to a view about whether the train will stop at T-town? And how can SSI recommend that Stanley believe something he doesn't know, according to SSI? Given Stanley's adherence to SSI, he would have to accept something Moore-paradoxical:

21 See DeRose 1995.

22 See also Blome-Tillmann 2009 for a similar problem with temporal and modal embeddings. 
(9) The train will stop at T-town but I don't know that and I don't even believe that.

Should Stanley then rather believe that not (1)? Should he (falsely) believe that

(10) Hawthorne does not know that the train will stop at T-town?

Well, if we also grant - which seems plausible, given our little scenario-that Stanley knows that

(11) If the train will stop at T-town, then Hawthorne knows it, then Stanley could easily infer from (10) and (11) that

(12) The train will not stop at T—town,

which is false. But recommending to believe something which entails something false, is not good advice. So, SSI should rather not recommend that Stanley believe the negation of (1) (Hawthorne knows that the train will stop at T-town).

The final option is suspension of belief about whether Hawthorne knows that the train stops at T-town. At the same time, Stanley should, taking SSI to heart, deny that he himself knows that / whether the train stops at T-town. But why suspension of judgment in Hawthorne's case when there is denial of knowledge in his own case? 
Stanley would be conceding the epistemic possibility that Hawthorne 'might' know that the train will stop at T-town. Stanley would then hold that the question whether the train will stop at $\mathrm{T}$-town is not settled for himself but that it might be settled for Hawthorne, even though they both share the same evidence. It is very doubtful that Stanley could coherently make sense of this situation.

More importantly, if Stanley believes that the question might be settled for Hawthorne, it would be rational or at least not unreasonable for him to just ask Hawthorne whether he knows whether the train will stop at $\mathrm{T}-$ town. ${ }^{23}$ Suppose he does so and suppose Hawthorne answers (correctly, according to SSI) that he does know that the train will stop at T-town. Suppose Stanley trusts Hawthorne's epistemic conscientiousness. Would he have any reason to reject Hawthorne's view or continue suspending judgment about it? What reason could that be? Perhaps that Hawthorne has lower stakes? But Stanley, the SSlist, could agree that it is possible that Hawthorne in his lower-stakes situation knows things he, Stanley, does not know. And if the conscientious fellow SSlist Hawthorne judges that he does know, how then could he, Stanley, doubt and suspend judgment about Hawthorne's claim? It is not irrational or unreasonable and certainly conceivable that Stanley would accept Hawthorne's claim and thus come not to suspend belief about Hawthorne's epistemic state and acquire a belief about it—which gets us back into the problems above.

23 Does this assumption change the case significantly because Hawthorne and Stanley now share a conversational context - which might affect their respective stakes? I don't think so but if one had this worry, one could easily change the case in such a way that the alleged problem disappears (e.g., by assuming that another passengers tells Stanley that Hawthorne knows that there will be a stop at T-town). 
If all this is true, then SSI has no good advice at all to offer about the question what Stanley should think about Hawthorne's epistemic state. SSI does not offer an answer to an important normative question: What should a subject with higher stakes think about the epistemic situation of a subject with lower stakes?

\section{A Last Resort: Epistemic Dynamics}

The defender of SSI could finally, as a last resort, embrace a very different strategy: deny (6) (Stanley does not know that / whether Hawthorne knows that the train will stop at T-town), accept (3) (Stanley knows that Hawthorne knows that the train will stop at T-town) and give a 'dynamic diagnosis' of the case. ${ }^{24}$ According to this idea, the argument needs to be modified slightly by adding a time-index. Here is the modified version (with $\mathrm{t}-2$ being later than $\mathrm{t}-1$ ). We have:

(1-t) Hawthorne knows at $\mathrm{t}-1$ (and later) that the train will stop at $\mathrm{T}$-town,

(2-t) Stanley doesn't know at $\mathrm{t}-1$ that (whether) the train will stop at $\mathrm{T}$-town,

$(3-\mathrm{t})$ Stanley knows at $\mathrm{t}-1$ (and later) that Hawthorne knows at $\mathrm{t}-1$ (and later) that the train will stop at $\mathrm{T}$ - town, and

(4-t) Stanley knows at $\mathrm{t}-1$ (and later) that if Hawthorne knows at $\mathrm{t}-1$ (and later) that the train will stop at $\mathrm{T}$ - town, then it will stop at $\mathrm{T}$ - town.

24 See also Brueckner and Buford 2009. 
From

(Closure-t) For all subjects $S$ and all propositions $p$ and $q$ : If $S$ knows at $t-1$ (and later) that $p$, also knows at $\mathrm{t}-1$ (and later) that $(p \rightarrow q)$, and comes to believe at $\mathrm{t}-2$, on the basis of competent deduction from the above two propositions, that $q$, then $S$ knows at $\mathrm{t}-2$ that $q$

plus $(3-t)$ and $(4-t)$ we can infer that

(5-t) Stanley knows at $\mathrm{t}-2$ that the train will stop at $\mathrm{T}$-town.

Stanley can come to know at $t-2$ that $(1-t)$ is true even if he did not know that at $t-1$. Problem solved? Contradiction gone?

Not quite! If The train will stop at $t$-town is a high—stakes proposition for Stanley at $\mathrm{t}-1$, then also at $\mathrm{t}-2$. The fact that Stanley can make a competent inference from what he knows to The train will stop at $t$-town does not change the stakes for The train will stop at $t$-town. How could it, given the arguments above? The proposition Hawthorne knows at $t-1$ (and later) that the train will stop at $T$-town can be lowstakes for Stanley while The train will stop at T-town is high-stakes for him. But if The train will stop at T-town is still high—stakes for Stanley, then SSI lacks the resources to solve the inconsistency problem by giving a dynamical diagnosis of the situation. 


\section{Conclusion}

The prospects for successfully defending (6) (Stanley does not know that / whether Hawthorne knows that the train will stop at $T$-town) seem very bleak. We should thus give up (6) and stick with (3): Stanley knows that Hawthorne knows that the train will stop at T-town. It appears to be an epistemological truism that barring very special circumstances a person can often know that another person knows a given proposition. A theory which denies or severely restricts this plausible principle has the burden of proof on its side and needs to come up with strong arguments against it (here against (3)). I have, on behalf of SSI, tried all serious arguments against (3) I could think of but they all fail. It is not just that SSI has its own problems - which theory hasn't got problems? The problems rather seem so serious that we should look for alternatives. However, if the SSlist does not give up (3) and continues to adhere to factivity and closure, then it is hard to see how they can avoid falling into the contradiction derived in section 1. Something has to go and it's SSI.

Acknowledgements: I am grateful for comments by members of the audience at a related talk at the University of Aberdeen and to several anonymous referees.

\section{References}

Baumann, Peter

2008 Contextualism and the Factivity Problem, in: Philosophy and Phenomenological Research 76, 580—602.

Baumann, Peter 
2012 Knowledge, Practical Reasoning and Action, in: Logos and Episteme 3, 7-26. Blaauw, Martijn

2008 Subject Sensitive Invariantism: In Memoriam, in: Philosophical Quarterly 58, $318-325$.

Blome-Tillmann, Michael

2009 Contextualism, Subject-Sensitive Invariantism, and the Interaction of 'Knowledge'-Ascriptions with Modal and Temporal Operators, in: Philosophy and Phenomenological Research 79, 315-331.

Brown, Jessica

2014 Shifty Talk: Knowledge and Causation, in: Philosophical Studies 167, 183-199. Brueckner, Anthony

2005 Contextualism, Hawthorne's Invariantism and Third—Person Cases, in:

Philosophical Quarterly 55, 315-318.

Brueckner, Anthony and Buford, Christopher T.

2009 Contextualism, SSI, and the Factivity Problem, in: Analysis 69, 431—438.

Davies, Martin

1998 Externalism, Architecturalism and Epistemic Warrant, in: Crispin Wright, Barry Smith and Cynthia Macdonald (eds.), Knowing Our Own Minds, Oxford: Clarendon, 321-361.

DeRose, Keith

1995 Solving the Skeptical Problem, in: The Philosophical Review 104, 1-52.

Dretske, Fred I.

1970 Epistemic Operators, in: The Journal of Philosophy 69, 1007-1023. 
Dretske, Fred I.

2005 The Case against Closure, in Mathias Steup and Ernest Sosa (eds.),

Contemporary Debates in Epistemology, Malden, MA: Blackwell, 13-26.

Fantl, Jeremy

2015 Interest-Relativity and Testimony, in: Social Epistemology Review and Reply Collective 4 (11), 40—46.

Fantl, Jeremy and McGrath, Matthew

2002 Evidence, Pragmatics, and Justification, in: The Philosophical Review 111, 6794.

Fantl, Jeremy and McGrath, Matthew

2009 Knowledge In an Uncertain World, Oxford: Oxford University Press.

Fantl, Jeremy and McGrath, Matthew

2012 Replies to Cohen, Neta and Reed, in: Philosophy and Phenomenological Research 85, 473—490.

Fricker, Elizabeth

1987 The Epistemology of Testimony, in: Proceedings of the Aristotelian Society, supplementary volume $61,57-83$.

Hawthorne, John

2004 Knowledge and Lotteries, Oxford: Clarendon.

Hawthorne, John and Stanley, Jason

2008 Knowledge and Action, in: The Journal of Philosophy 105, 571—590.

Howell, Robert J.

2005 A Puzzle for Pragmatism, in: American Philosophical Quarterly 42, 131-136. 
MacFarlane, John

2005 Knowledge Laundering: Testimony and Sensitive Invariantism, in: Analysis 65, $132-138$.

Moeller, Emil Frederik Lundbjerg

2015 Consuming Knowledge Claims across Contexts, in: Synthese 192, 4057-4070.

Montminy, Martin and Skolits, Wes

2014 Defending the Coherence of Contextualism, Episteme 11, 319-333.

Neta, Ram

2007 Anti-Intellectualism and the Knowledge-Action Principle, in: Philosophy and Phenomenological Research 75, 180—187.

Neta, Ram

2012 The Case against Purity, in: Philosophy and Phenomenological Research 85, 456-464.

Nozick, Robert

1981 Philosophical Explanations, Cambridge/MA: Harvard University Press.

Stanley, Jason

2005 Knowledge and Practical Interests, Oxford: Clarendon.

Williamson, Timothy

2005 Contextualism, Subject-Sensitive Invariantism, and Knowledge of Knowledge, in: Philosophical Quarterly 55, 213-235.

Wright, Crispin

1985 Facts and Certainty, in: Proceedings of the British Academy 71, 429-472.

Wright, Crispin 
2005 Contextualism and Scepticism: Even-Handedness, Factivity and Surreptitiously Raising Standards, in: Philosophical Quarterly 55, 236-262. 